\title{
Sexual Orientation and Family Development: Introduction
}

\author{
Brian W. Litzenberger, Ph.D., and Margaret C. Buttenheim, Ph.D.
}

$\mathrm{T}$ his special section focuses on articles that challenge longstanding assumptions about the relationship between sexual orientation and gender as they develop within families. Because traditional gender roles are based on a heterosexual orientation, homosexuality disrupts not only expectations about the love object, but also expectations about gender itself. Such disruptions, no matter when they emerge in the development of an individual, inevitably influence all members of the family. Homosexuality disrupts theory and culture in different ways. The existence of healthy gay and lesbian individuals, and their capacity to create families with healthy children, necessitates a fundamental reexamination of our theories about development. As the papers in this section illustrate, we do not currently have theories that adequately explain nonpathological homosexual development and its impact on the individual and family. The time has come to revise the axioms of developmental theory.

\section{THE CHALLENGES TO THEORY}

First, numerous empirical studies have failed to differentiate homosexual and heterosexual individuals on a variety of measures constituting "mental health" (Baumrind, 1995; French, Story, Remafedi, \& Resnick, 1996; Gallois, Troy, Timmins, \& Kashimar, 1994; Hiatt \& Hargrave, 1994; Mitz, Rosser, \& Strapko, 1994; Patterson, 1995; Schreurs \& Buunk, 1994). That is, the long held assumption about the relationship between heterosexuality and "normality" has been shattered. Beginning with Hooker's (1957) famous experiment that failed to differentiate homosexuals and heterosexuals on the Rorshach test, numerous studies have found homosexuals and heterosexuals indistinguishable in terms of a number of criteria. As to mental health, the evidence shows that homosexuals are no more or less pathological than their heterosexual counterparts.

Secondly, due to the extensive political activity that has brought about, at least in some enclaves, greater tolerance, increasing numbers of gay men and lesbians are creating visible families with children. Gay men and lesbians raising children is not in itself new; many have had children in the context of heterosexual relationships and have raised them after those relationships have broken up (Bozett, 1981; Laird, 1993). What is new is the large number of lesbians and gay men who are choosing parenthood, and doing so in a variety of new family structures (Gartrell, Hamilton, Banks, \& Mosbacher, 1996). The desire of many individuals of both sexes to procreate and to parent in the context of a profound and primary attachment to someone of the same sex challenges the developmental theory that assumes that the wish to parent is the ultimate expression of appropriate, heterosexual gender development.

Thirdly, as gay men and lesbians create families of their own, they step outside the model traditionally thought to be essential for the development of psychologically healthy children with appropriate genders and "corresponding" sexual orientations. Once again, the research findings are at variance with expectations derived from theory. Empirical research indicates

This special section was organized for the Journal by the authors, who are at: Traumatic Stress Institute, Center for Adult and Adolescent Psychotherapy, South Windsor, Conn. (Litzenberger); and University Center for the Child and the Family, Department of Psychology, University of Michigan, Ann Arbor (Buttenheim). 
that children raised in gay and lesbian households fare as well as do the children raised by heterosexuals (Hoeffer, 1981; Kirkpatrick, Smith, \& Roy, 1981; Savin-Williams, 1995). These findings pose profound challenges to theory about how children make use of same- and differentsexed adults to acquire gender identity and sexual orientation.

Traditional theories of individual development cannot account for these findings. These theories have posited a "normal" route to maturity whereby a child takes as a love object the parent of the opposite sex and identifies with the gender characteristics of the same-sex parent (Beard \& Glickauf-Hughes, 1994; Ferguson, 1994; Lilling \& Friedman, 1995). In this model, dichotomized systems of gender and sexual orientation sustain each other. It is the child's desire for the opposite-sex parent that facilitates the taking on of the gender characteristics of the same-sex parent, and it is identifications with the same-sex parent that encourages desire for the opposite-sex parent. In this way, at least for the girl, wishes to have babies are thought to develop in the context of wishes to have the father's baby as the mother did. In this model, there is room for minor identifications with the opposite-sex parent and for fleeting or sublimated bisexual longings, but these are expected to remain minor leitmotifs. Children and adults who do not behave in these expected ways have been regarded as theoretical and cultural abnormalities, and have been fair game for prejudicial treatment (Buttenheim \& Contratto, 1993).

Implicit in these models of individual development is an expected family structure consisting of a male and a female parent. In theorizing about parenting, it is assumed that the psychological tasks involved will be shared by two people of opposite sexes. For instance, we have no theory that would account for two women allowing themselves, and each other, both to have a maternal identification in relation to their shared child. With regard to children, theory holds that the availability at close hand of two differently sexed objects, cathected and available for gendered identifications, is essential for the normal development of the child. For instance, it is assumed that the availability of differently sexed parents facilitates the essential transition from dyadic to triadic relationships. Just as there is no theory to explain how two people of the same sex psychologically share parenting, there is no theory to explain how children of same-sex parents develop into psychologically healthy adults.

\section{GENDER, CULTURE, AND MENTAL HEALTH}

Theories of the development of sexual orientation have been inextricably intertwined with dominant cultural assumptions about mental health and gender (Laird, 1993). Across the life span, cultural rituals serve to (re)enforce heterosexual manifestations of gender identity and behavior. Research on infant development demonstrates the different ways that boy and girl babies are handled and talked to (Lewis, Scully, \& Condor, 1992; Smith \& Lloyd, 1978). Female toddlers and preschoolers are encouraged to play house, while male toddlers are given trucks, replicating the gendered roles of their parents and enacting what is assumed to be the first stages of the identifications that will advance their development (Robinson, Little, \& Biringen, 1993; O'Brien $\&$ Nagle, 1987). From latency-aged games to the high school prom, heterosexuality is rewarded and coded in a complex system of self-perpetuating checks and balances. The discrepancies between the support and education provided for the development of heterosexuality and the silence that surrounds the possibility of homosexual development forces homosexuality to be an aspect of the self that is self-discovered in ways that almost invariably remain lonely and private.

Recent controversies have highlighted the quandaries for gay men and lesbians that are created by these rituals. From debates about same-sex marriage to battles for domesticpartner health benefits to legal disputes over child custody, the current political and cultural environment is rife with examples of the inadequacies of social structures to meet the needs of gay and lesbian people and their children (Stevens, 1993). Further, current cultural rhetoric and political platforms reinforce the message that the existence of gay and lesbian families is a threat that needs to be combated. This type of political and social stigma, reflecting both personal attitudes and government policy, illuminates an area that is grievously in need of correction.

Given that research findings have consistently pointed to stigma as the primary source of the problems in the lives of lesbians and gay men (Garnets, Herek, \& Levy, 1990; Greene \& Boyd-Franklin, 1996; Herek \& Berrill, 1990; 
Meyer, 1995; Ross \& Rosser, 1996), reform of public policy is needed to ensure that a homosexual identity is as respected and supported as a heterosexual identity. Research has shown that gay and lesbian individuals come from a variety of family contexts and developmental pathways (Burch, 1993a), and that this identity is not generally subject to change (Haldeman, 1994). Consequently, cultural and educational reforms are essential to address the unmet needs of those children who will develop into gay or lesbian adults, so as to prevent them from suffering the self-hating internalizations that now lie in wait for them in our society.

Theory and research suggest that there are specific developmental moments when homosexuality is more likely to become visible, points at which there is often a confrontation involving the individual, the family, and society (Cass, 1979; Faderman, 1984; Isay, 1989). When heterosexual expectations and homosexual realities clash, individuals and families are particularly at risk for psychological distress (Litzenberger, 1994). For example, the heterosexual family's response to the announced homosexuality of one of its children often leads to a period of emotional upheaval, and occasionally to physical violence (Anderson, 1993-94; Steel \& Guldner, 1993). Similarly, research on the children of gay and lesbian parents highlights a time of difficulty in their adolescence related to peers' understanding of their parents' sexuality (Tasker \& Golombok, 1995).

Clinical reports of gay men and lesbians' experiences of their sexual education, both in the family and in the schools, have pointed out omissions that have contributed to feelings of alienation and confusion about sexuality and identity (Duckitt \& du Toit, 1989; Garnets \& D'Augelli, 1994; O'Conor, 1993-94; Savin-Williams, 1989). These examples articulate the distress that occurs in the clash between societal assumptions of heterosexuality and an individual or family's experience of homosexuality. To begin to address these problems, it is necessary to confront the ways in which assumptions of heterosexuality permeate our psychological theory and practice (Garnets, Hancock, Cochran, \& Goodchilds, 1991).

In summary, research on gay and lesbian experiences conflicts with theories of sexual development. This conflict underscores both the unique characteristics of these experiences and the absence of a theory of gay and lesbian de- velopment that could account for them. Some research has begun to confront this problem by exploring these unexpected, unusual, and unaddressed phenomena. As fundamental assumptions about sexuality are challenged, what begins to emerge is the necessity for models that would be inclusive of homosexual and heterosexual development.

\section{OVERVIEW OF ARTICLES}

Within this special section, we envision models that would accommodate traditional masculine gender development of a young boy who will develop into a gay man; models that could predict family reactions to a child's homosexuality; models that could account for a boy child's conception of "mother" in a family headed by two women; models that could assess the variables associated with high- versus lowconflict lesbian divorce. The papers in this section are innovative in this way; all provide new understandings of "marginal" phenomena and point us in directions for new theoretical conceptualizations of psychosexual development.

Current writing on lesbian and gay development comes from diverse perspectives, many of which are represented in this section. They include the views of clinicians, researchers, policy makers, and activists. These authors address child, adolescent, and adult development, and they examine individual, family, and cultural dynamics. All in all, we mean to spark discussion and to engage mental health professionals in questioning the foundations of their work as these conflict and coincide with the evidence of the lives discussed in these articles.

In the first paper, Ken Corbett describes the psychological experiences of a subset of "gay boys" who had cross-gendered identifications as children. This topic has, on many counts, been avoided by those who feared that its acknowledgment would communicate that all gay men are feminine, a complicated and misogynistic idea carrying a great deal of political power. Ironically, as Corbett elaborates here, it is the avoidance of discussing feminine identifications in gay men that has the paradoxical effect of stigmatizing them further. He is careful to point out that not all feminine men are gay and that not all gay men are feminine, but that this subgroup of gay men who did experience themselves in this way have eluded understanding. Unlike many who have written before him, Corbett is not concerned with the origins of 
these identifications, but with their effects on the relational and emotional lives of these men.

Based on his clinical observations and an analysis of related theoretical material, Corbett suggests that the state of the field has been to label those children who do not conform to gender stereotypes as pathological. This stems from a confusion between manifest gender and psychological health (the conflation of which he terms "gender health"), a confusion that has resulted in the field of psychology contributing to experiences of isolation and shame. He argues that psychological health does not require that one's behavior be aligned with traditional notions of what is appropriate to one's biological sex. Rather, psychological health is a matter of consistency between external gendered behavior and internal identifications. He offers evidence that it is reclaiming cross-sex identifications, rather than eschewing them, that leads to psychological health for these men. The key for the gay man troubled by these identificationsand for the theory-is to reject binary categories of gender and to accept the multiplicity of gender identifications that comprise most people's experience of their gender (Burch, 1993b).

Next, D'Augelli, Pilkington, and Hershberger report results of a cross-sectional study that reached a population often unseen and unheard: youth who self-identify as lesbian and gay during their teenage years. By comparing those who had disclosed their sexual orientation to their families and those who had not, the authors elucidate prominent aspects of the coming-out process for those on both sides of the family closet door. Continuing the work of others who have shown that sexual feelings emerge at young ages (McClintock \& Herdt, 1996: Savin-Williams, 1995), this study documents the existence of a cohort of children who are perceiving their sexual orientation to be gay or lesbian at a much younger age (ten years, on average) than is often thought. That this is true draws attention to the dearth of support available to these fourth- and fifth-grade children. As these children describe their experiences of isolation, they are describing the ways that they do not fit the prevailing messages about gendered expectations for love and sexuality.

This paper is accompanied by a commentary from Mitzi Henderson, former national president of Parents and Friends of Lesbians and Gays (PFLAG), whose experience with families struggling to integrate new understandings of homosexuality enables her to provide a longitudinal perspective on this cross-sectional study and to suggest the time-limited nature of some of its findings. Her discussion helps to fill in the context within which D'Augelli et al.'s adolescents develop, and to highlight the need for longitudinal research on the ways that gay and lesbian children develop in family contexts.

Cheryl Parks provides a review of what is currently known about lesbian families, based on two decades of research; it is followed in this section by several articles that explore in depth questions raised by this review. As Parks makes clear, there is now a sizable and sound body of research on this topic-research that coalesces around clear trends and areas for future inquiry, and that provides data in support of some of the axioms underlying the current special section, e.g., that children growing up in gay families are no more or less pathological than those raised in heterosexual families. Parks's paper touches on some problematic research questions (such as, who is a lesbian?) with profound implications for empirical research. It also suggests the possibility that aspects of family organization more typical in families headed by two parents of the same sex, namely greater egalitarianism, could have positive effects on children's development.

Little is known about the similarities and differences between heterosexual and lesbian or gay parents and families. Patterson, Hurt, and Mason step into this void in the next paper and refute the stereotypes of lesbian parents as isolated and isolating of their children (Gottman, 1989). By investigating these mothers' relationships with their families of origin and friendship networks, this research documents the contact that children of lesbian couples have with grandparents and other adults outside of the family, and the impact of these contacts on the children. The study further shows that many lesbians, like many heterosexual women, have a strong desire to mother and to involve their children with their own families of origin (Contratto \& Buttenheim, 1993). In addition, Patterson et al. find that these women's children are also in regular contact with extrafamilial adults, both homosexual and heterosexual

Valory Mitchell next reports results of her investigation into the ways in which lesbian parents talk to their children about sex. Predictably, some of these conversations address the parents' own sexual orientation. But communication 
does not end there. In her descriptions of those serendipitous moments that put a parent on the spot and also open a door for sexual education, Mitchell shows how these women encourage their children to feel comfortable with their own sexuality regardless of the child's future sexual orientation. This research includes only lesbian families, precluding comparisons with heterosexual households or with households headed by gay men, and similar strategies could be common to other settings. In many respects, however, the ways lesbians talk to their children about sex seem unique. Mitchell highlights these in her discussion and addresses their potential for changing the way heterosexual parents and schools approach the sexual education of children.

In what may be the first paper to address this legally anomalous phenomenon, Susan Morton examines lesbian "divorce." She explores new ground in theorizing about the psychological and logistical aspects of this experience, and notes, as have others (Burch, 1982), that forces within the lesbian community as well as those from the psychological community have contributed to the relative silence on this topic. Morton acknowledges both that lesbians are making major life commitments to each other and that, in some cases, these commitments do not work; in the latter circumstances, separation may be complicated and painful. Fundamental to this paper is the assertion that the basic emotional distress that lesbians undergo as they divorce is the same as that undergone by heterosexual couples. Lesbians who have children struggle over sharing the role of mother, and can continue to do so after a divorce. In addition, Morton raises central questions about the psychological implications of a legal system that recognizes neither lesbian unions nor their separations.

From the perspective of a legal scholar, David Chambers elaborates on some of the issues raised by Morton. In examining the current state of the law governing same-sex relationships and parenting, Chambers clarifies similarities and differences in the law's treatment of gay or lesbian couples and unmarried heterosexual couples. His commentary encompasses both the unions and separations of same-sex couples. As an aid to couples and to therapists treating lesbian or gay clients, he outlines steps a same-sex couple may take while in a healthy relationship to prepare for the possibility, however unbid- den, of the relationship breaking up. In doing so, he concurs with Morton's thesis that external and carefully considered structures are needed to facilitate separations. Chambers provides direction for policy makers concerned with redressing institutionalized inequality while, at the same time, clarifying the ways in which marriage, as it is legally defined, may not suit the needs of all lesbian or gay couples.

In the first of two clinical papers, Richard Isay writes about gay men who have come out in middle age- a group highly underrepresented in the literature. He presents psychoanalytic case histories of three heterosexually married men whose treatment centered on their attraction toward other men. Isay's conceptualization of these patients' sexual orientation is that they were always gay men who, because of their particular family constellations and early object relations, responded to the societal pressures against homosexuality by leading a "false" life and marrying. He elaborates the processes through which these life decisions were made and the emotional struggles that these men faced, including the posttreatment suicide of one of them. In seeking to help these men confront their own perceptions of their sexuality as sickness and grapple with the complications and entanglements of their marriages-and in writing about it-Isay directly counters the persistent assumption of traditional psychoanalysis that the appropriate and psychologically healthy outcome must be a heterosexual one.

In a very different case history, Barbara Eisold describes the two-year treatment of the young son of a gay male couple. Contrary to early vitriolic predictions that gay couples would "make" children gay (Fowler, 1995; Green, 1982), the boy's main affectional attentions are toward women. He articulates the desire to grow up, be a man, and "marry with a wife." This paper is particularly valuable in its focus on the unique aspects of the "two-dad" family, and the dearth of theoretical tools to comprehend and support this very little know family form. Further, Eisold's paper makes clear just how little we understand as yet about the development of sexual orientation, even heterosexual orientation, in childhood.

Eisold, as therapist, and the boy's two fathers have ventured into a realm that has only begun to be explored. The particularity of the fathers' choices-i.e., not disclosing to the child their sexual orientation and mutual commitment; hir- 
ing a series of women (including the therapist) to serve as caregivers - necessarily limits the generalizability of this paper. They may have limited, as well, their son's understanding of the depth, commitment, and love of his parents' relationship. The effects of these decisions on the boy and his treatment raise significant questions about theory and clinical practice, and outline the struggles that we undergo as we step into this work. In her commentary on Eisold's paper, Karen Saakvitne stresses the psychoanalytic implications of missing the impact of early object loss upon subsequent developmental struggles. Her critique reminds us of the multiple determinants of sexual orientation and cautions against theory that moves us too quickly away from the ambiguities of development.

The final paper shifts our focus from within the family to the family's interaction with the community. Steven James describes the efforts that some communities and individuals have undertaken to make a difference for gay and lesbian youth and families. Through an examination of the research, James provides us with models from around the country; through recounting what has happened in his own community, he gives us a detailed description of a process that often arises in response to homophobic incidents. James emphasizes what the other papers in this section also assert: that the effect on the individual is mediated by the nature of family and community response. The parent-child relationships that are often at the center of these movements (e.g., PFLAG, as described in the earlier commentary by Henderson), are augmented by those other relationships that we form over drugstore counters and boardroom tables. Gay activists proclaim coming out as the most powerful method of social action. This model is not just about people of diverse sexual orientations coming out, but about being out. In this way, James describes how communities can take responsibility for all children.

\section{TOWARD A NEW}

\section{UNDERSTANDING OF SEXUALITY}

The articles that make up this special section tend to focus on issues of child development, the process of coming out, or family dynamics. It is clear that times are changing-somewhat faster than we are able to document. Children are becoming aware of their sexual orientation at earlier ages and, as pioneers, coming out in their schools and forcing changes in the systems within which they exist. Lesbian and gay couples are creating families with children and demanding equal recognition from their communities. Without stories of procreation to rely on, these same parents are forging new ways of discussing relationships and sexuality with their children. As researchers and clinicians, we are in the position to bear witness to these experiences and to construct theories that may also facilitate this development. The diverse and often conflicting points of view of the theorists, clinicians, empirical researchers, and activists collected here are united in pushing against the boundaries of traditional theory, in offering new insights into gay and lesbian development, and in presenting challenges for future work.

In bringing together these articles, we hoped that their discussion of lesbian and gay lives would inform a new understanding of heterosexuality as well. This has already occurred in race theory, which has sensitized us to the notion that whites as well as blacks have "race," and in feminist theory, which has taught us that men, too, have gender. It is our hypothesis that the pathologizing of homosexuality has functioned much the same way as has the pathologizing of race (Greene \& Boyd-Franklin, 1996), namely to project upon a disfavored minority facets of experience that the culture rejects.

One of the clearest implications of the papers in this section is that visibility and acceptance are central aspects of growth. Children need out and open role models to provide them with visions of possible future selves. Sexually emergent adolescents need environments in which gay and lesbian sexuality is a viable and accepted mode of expression. Adults need communities that value and respect same-sex relationships. Families need positive understandings of child and adult development that encompass diverse sexualities. Mental health workers and researchers need resources and ideas to help explore and provide for the changes that are needed to facilitate this same growth.

Because we now understand that homosexuality is a developmental outcome as full of possible joy and strife as heterosexuality, we need to make the space in all our work for this to become an experienced reality. We aim to shift the focus of the analysis to sexuality, stripped of its hetero and homo prefixes. The important inquiry is not the sex of the partner but the nature of the sexual relationship, not whom you love but how well you do it. We believe that the emer- 
gent theory should act as good parenting would. It should provide options for lots of positive ways to turn out. It should situate the development of sexual orientation within a broader object relational, developmental theory that would provide clinicians and parents with guidelines for healthy relational development. These guidelines would describe how people choose, discover, conceptualize, and become sexually related to others.

Our theoretical frameworks conflict in many significant areas. Is sexual orientation inborn or constructed? Do we place as primary the development of the individual or the family? If we think behaviorally or psychoanalytically, how do we miss the boat on understanding the identity struggles of two parents of the same sex? Notice that the papers that address sexual orientation in childhood are primarily focused on males, and that those addressing families are primarily focused on females. We are limited by our own constructions of gender and sexual orientation even as we attempt to deconstruct them through research. These articles articulate this struggle and the extent to which it is ingrained in us - in our thinking and our language, in our research and our practices. We hope, through presenting these papers, to open discussion and take an additional step forward in clinical practice, theory development, research, and policy making that is inclusive of all women and men and families across the life span and across sexual orientations.

\section{REFERENCES}

Anderson, D. (1993-94). Lesbian and gay adolescents: social and developmental considerations. High School Journal, 77(1-2), 13-19.

Baumrind, D. (1995). Commentary on sexual orientation: Research and social policy implications. $D e$ velopmental Psychology, 31, 130-136.

Beard, J., \& Glickauf-Hughes, C. (1994). Gay identity and sense of self: rethinking male homosexuality. Journal of Gay and Lesbian Psychotherapy, 2(2), 21-37.

Bozett, F. (1981). Gay fathers: evolution of the gayfather identity. American Journal of Orthopsychiatry, 51, 552-559.

Burch, B. (1982). Psychological merger in lesbian couples: a joint ego psychological and systems approach. Family Therapy, 9, 201-208.

Burch, B. (1993a). Gender identities, lesbianism, and potential space. Psychoanalytic Psychology, 10, 359-375.

Burch, B. (1993b). Heterosexuality, bisexuality, and lesbianism: rethinking psychoanalytic views of women's sexual object choice. Psychoanalytic Review, 80, 83-99.
Buttenheim, M., \& Contratto, S. (1993). [Book review of Female Homosexuality: Choice Without Volition by Elaine V. Seigel.] Psychoanalytic Psychology, 10, 463-468.

Cass, V.C. (1979). Homosexual identity formation: A theoretical model. Journal of Homosexuality, 4, 219-235.

Contratto, S., \& Buttenheim, M. (1993). [Book review of Lesbian Mothers: Accounts of Gender in American Culture by Ellen Lewis, and Family Values: Two Moms and their Son, by Phyllis Burke.] Women's Review of Books, $1 /(2), 24-25$.

Duckitt, J., \& du Toit, L. (1989). Personality profiles of homosexual men and women. Journal of Psychology, 123, 497-505.

Faderman, L. (1984). The "new gay" lesbians. Journal of Homosexuality, 10(3/4), 85-95.

Ferguson, M. (1994). Fixations and regression in the psychoanalytic theory of homosexuality: a critical evaluation. Journal of Homosexuality, 27(3-4), 309-327.

Fowler, J. (1995). Homosexual parents: Implications for custody cases. Family and Conciliation Courts Review, 33, 361-376.

French, S., Story, M., Remafedi, G., \& Resnick, M. (1996). Sexual orientation and the prevalence of body dissatisfaction and eating disordered behavior: A population-based study of adolescence. International Journal of Eating Disorders, 19(2), 119-126.

Gallois, C., Troy, D., Timmins, P., \& Kashimar, Y, (1994). Safe sexual intentions and behavior among heterosexuals and homosexual men: testing the theory of reasoned attention. Psychology and Health, 10(1), 1-16.

Garnets, L., \& D'Augelli, A. (1994). Empowering lesbian and gay communities: A call for collaboration with community psychology. American Journal of Community Psychology, 22, 447-470.

Garnets, L, Hancock, K., Cochran, S., \& Goodchilds, J. (1991). Issues in psychotherapy with lesbians and gay men: A survey of psychologists. American Psychologist, 46, 964-972.

Garnets, L, Herek, G., \& Levy, B. (1990). Violence and victimization of lesbians and gay men: mental health consequences. Journal of Interpersonal $\mathrm{Vi}$ olence, 5, 366-383.

Gartrell, N., Hamilton, J., Banks, A., \& Mosbacher, D. (1996). The national lesbian family study: I. Interviews with prospective mothers. American Journal of Orthopsychiatry, 66, 272-281.

Gottman, J. (1989). Children of gay and lesbian parents. Marriage and Family Review, 14(3-4), 177-196.

Green, R. (1982). The best interests of the child with a lesbian mother. Bulletin of the American Academy of Psychiatry and the Law, 10(1), 7-15.

Greene, B., \& Boyd-Franklin, N. (1996). African American lesbian couples: ethnocultural considerations in psychotherapy. Women and Therapy, $19(3), 49-60$.

Haldeman, D. (1994). The practice and ethics of sexual orientation conversion therapy. Journal of Consulting and Clinical Psychology, 62, 221227. 
Herek, G., \& Berrill, K. (1990). Antigay violence and mental health: setting an agenda for research. Journal of Interpersonal Violence, 5, 414-423.

Hiatt, D., \& Hargrave, G. (1994). Psychological assessment of gay and lesbian law enforcement applications. Journal of Personality Assessment. 63(1), 80-88.

Hoeffer, B. (1981). Children's acquisition of sex-role behavior in lesbian-mother families. American Journal of Orthopsychiatry, 51, 536-544.

Hooker, E. (1957). The adjustment of the male overt homosexual. Journal of Projective Techniques, $21,18-31$.

Isay, R. (1989). Being homosexual: Gay men and their development. New York: Avon Books.

Kirkpatrick, M, Smith, C., \& Roy, R. (1981). Lesbian mothers and their children: a comparative survey. American Journal of Orthopsychiatry, 51, 545-551.

Laird, J. (1993). Lesbians and lesbian families: multiple reflections. Smith College Studies in Social Work, 63, 209-213.

Lewis, C., Scully, D., \& Condor, S. (1992). Sex stereotyping of infants: a re-examination. Journal of Reproductive and Infant Psychology, 10, 53-61.

Lilling, A., \& Friedman, R. (1995). Bias towards gay patients by psychoanalytic clinicians: an empirical investigation. Archives of Sexual Behavior, 24, $562-570$.

Litzenberger, B. (1994). Struggles and strengths in the lives of two lesbian priests. In A. Stewart \& C. Franz (Eds.), Women creating lives: Identity, resistance, and resilience (pp 273-288). Boulder, CO: Westview Press.

McClintock, M, \& Herdt, G. (1996). Rethinking puberty: The development of sexual attraction. Current Direction in Psychological Science, 5(6), 178-183.

Meyer, I. (1995). Minority stress and mental health in gay men. Journal of Health and Social Behavior, 36, 38-56.

Mitz, M., Rosser, B., \& Strapko, N. (1994). Differences in conflict-resolution styles among hetero- sexual, gay, and lesbian couples. Journal of Sex Research, 31, 293-308.

O'Brien, M., \& Nagle, K. (1987). Parents' speech to toddlers: The effect of play context. Journal of Child Language, 14(2), 269-279.

O'Conor, A. (1993-1994). Who gets called queer in school? Lesbian, gay, and bisexual teenagers, homophobia and high school. High School Journal, $77(1-2), 7-12$.

Patterson, C. (1995). Sexual orientation and human development: An overview. Developmental Psychology, 31, 3-11.

Robinson, J., Little, C., \& Biringen, Z. (1993). Emotional communications in mother-toddler relationships: evidence for early gender differentiation. Merrill-Palmer Quarterly, 39, 496-517.

Ross, M., \& Rosser, B. (1996). Measurement and correlates of internalized homophobia: a factor analytic study. Journal of Clinical Psychology, 52, 15-21.

Savin-Williams, R. (1989). Coming out to parents and self-esteem among gay and lesbian youths. Journal of Homosexuality, 18(1-2), 1-35.

Savin-Williams, R. (1995). An exploratory study of pubertal maturation timing and self-esteem among gay and bisexual male youths. Developmental Psychology, 31, 56-64.

Schreurs, K., \& Buunk, B. (1994). Intimacy, autonomy, and relationship satisfaction in Dutch lesbian couples and heterosexual couples. Journal of Psychology and Human Sexuality, 7(4), 41-51.

Smith, C. \& Lloyd, B. (197). Maternal behavior and perceived sex of infant: Revisited. Child Development, 49, 1263-1265.

Steel, M., \& Guldner, C. (1993). Identifying and meeting the needs of gay and lesbian adolescents in family therapy. Canadian Journal of Human Sexuality, 2, 1-12.

Stevens, P. (1993). Lesbians and HIV: clinical, research, and policy issues. American Journal of Orthopsychiatry, 63, 289-294.

Tasker, F., \& Golombok, S. (1995). Adults raised as children in lesbian families. American Journal of Orthopsychiatry, 65, 203-215. 